\title{
Improving Crystalline Silicon Solar Cell Efficiency Using Graded-Refractive-Index SiON/ZnO Nanostructures
}

\author{
Yung-Chun Tu, ${ }^{1}$ Shui-Jinn Wang, ${ }^{1,2}$ Chien-Hung Wu, ${ }^{3}$ Kow-Ming Chang, ${ }^{4}$ \\ Tseng-Hsing Lin, ${ }^{1}$ Chien-Hsiung Hung, ${ }^{1}$ and Jhen-Siang $\mathrm{Wu}^{1}$ \\ ${ }^{1}$ Institute of Microelectronics, Department of Electrical Engineering, National Cheng Kung University, Tainan 701, Taiwan \\ ${ }^{2}$ Advanced Optoelectronic Technology Center, National Cheng Kung University, Tainan 701, Taiwan \\ ${ }^{3}$ Department of Electronics Engineering, Chung Hua University, Hsinchu 300, Taiwan \\ ${ }^{4}$ Department of Electronics Engineering, National Chiao Tung University, Hsinchu 300, Taiwan
}

Correspondence should be addressed to Shui-Jinn Wang; sjwang@mail.ncku.edu.tw

Received 24 November 2014; Accepted 30 December 2014

Academic Editor: Shyh-Jer Huang

Copyright (C) 2015 Yung-Chun Tu et al. This is an open access article distributed under the Creative Commons Attribution License, which permits unrestricted use, distribution, and reproduction in any medium, provided the original work is properly cited.

The fabrication of silicon oxynitride $(\mathrm{SiON}) / \mathrm{ZnO}$ nanotube $(\mathrm{NT})$ arrays and their application in improving the energy conversion efficiency $(\eta)$ of crystalline Si-based solar cells (SCs) are reported. The SiON/ZnO NT arrays have a graded-refractive-index that varies from 3.5 ( $\mathrm{Si}$ ) to $1.9 \sim 2.0\left(\mathrm{Si}_{3} \mathrm{~N}_{4}\right.$ and $\mathrm{ZnO}$ ) to $1.72 \sim 1.75$ ( $\left.\mathrm{SiON}\right)$ to 1 (air). Experimental results show that the use of $0.4 \mu \mathrm{m}$ long ZnO NT arrays coated with a $150 \mathrm{~nm}$ thick SiON film increases $\Delta \eta / \eta$ by $39.2 \%$ under AM $1.5 \mathrm{G}\left(100 \mathrm{~mW} / \mathrm{cm}^{2}\right)$ illumination as compared to that of regular SCs with a $\mathrm{Si}_{3} \mathrm{~N}_{4} /$ micropyramid surface. This enhancement can be attributed to SiON/ZnO NT arrays effectively releasing surface reflection and minimizing Fresnel loss.

\section{Introduction}

Surface roughening through the chemical wet etching process $[1,2]$, nanoimprint lithography [3], and nanostructures $[4,5]$ has been applied to roughen the top surface of optoelectronic devices. Surface roughening has attracted considerable interest for applications such as solar cells (SCs), light-emitting diodes (LEDs), ultraviolet photodetectors (UV-PDs), and gas sensors [6-9]. A suitably roughened surface can significantly improve the surface reflectivity of SCs, alleviate the total internal reflection of LEDs, and increase the responses of UVPDs and gas sensors [6-9]. However, most surface roughening methods involve expensive lithographic patterning or cumbersome fabrication processes and can even deteriorate electrical properties, making them unsuitable for mass production.

Zinc oxide $(\mathrm{ZnO})$ is a promising material for surface roughening. It has a wide direct band gap $(3.37 \mathrm{eV}$ at room temperature), large exciton binding energy (about $60 \mathrm{meV}$ ) $[10,11]$, and transmittance of about $85 \%$ in the visible region $[12,13]$. One-dimensional $\mathrm{ZnO}$ nanowire (NW) arrays have received great attention due to their ease of fabrication, low-temperature processing, and unique properties, such as large length-to-diameter ratio, high surface-to-volume ratio, and carrier confinement, which could improve device performance $[6,14-16]$. Nevertheless, the transmittance of $\mathrm{ZnO} \mathrm{NW}$ arrays needs to be improved for light transmission in the visible-light spectrum.

To further improve the light trapping efficiency (LTE) and light transmission of SCs in the visible region, a simple and cost-effective surface roughening scheme that employs $\mathrm{SiON} / \mathrm{ZnO}$ nanotube (NT) arrays is proposed in this work. The scheme is expected to reduce the Fresnel loss effect from a graded-refractive-index structure. The optoelectronic characteristics of regular SCs and those with the proposed $\mathrm{SiON} / \mathrm{ZnO} \mathrm{NT}$ arrays, ZnO NT arrays, and conventional $\mathrm{ZnO} \mathrm{NW}$ arrays, respectively, are compared and discussed.

\section{Experiments}

Figure 1 schematically shows the four types of SC, namely, SC-A, SC-B, SC-C, and regular SC, prepared in this study. 


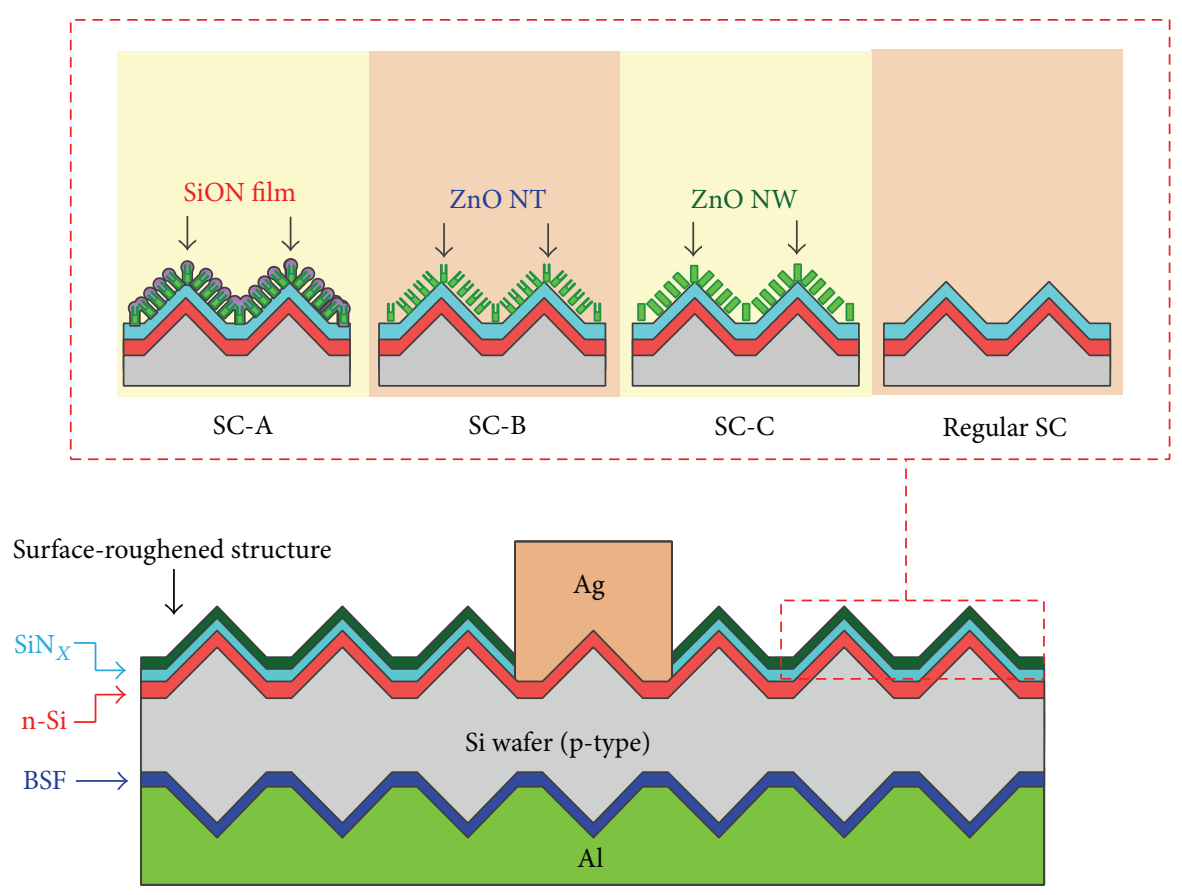

FIgURE 1: Schematic device structures of SC-A (with SiON/ZnO NT arrays), SC-B (with ZnO NT arrays), SC-C (with ZnO NW arrays), and regular SC (with $\mathrm{KOH}$-etched surface).

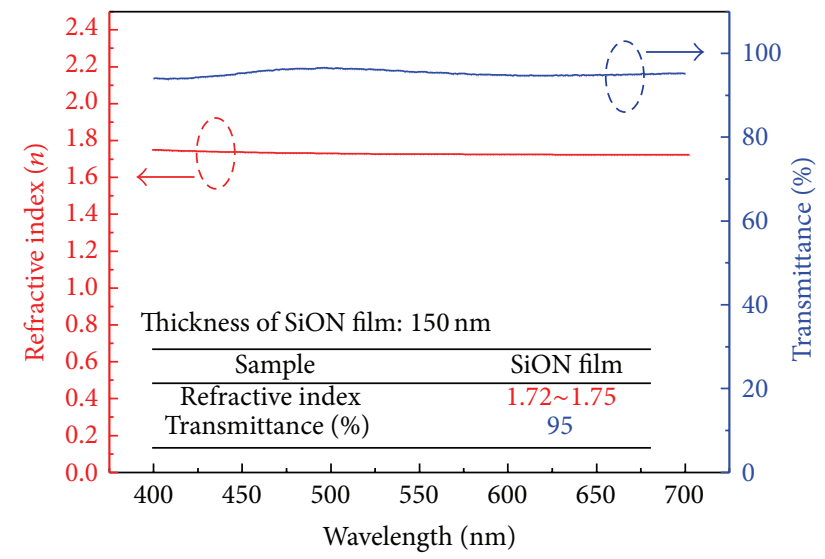

FIGURE 2: Measured transmittance and refractive index of SiON film (150 $\mathrm{nm}$ in thickness).

The regular SCs, prepared using the standard fabrication process, had a $\mathrm{KOH}$-etched micropyramid surface and a $\mathrm{Si}_{3} \mathrm{~N}_{4}$ antireflection (AR) coating. For some of the regular SCs, $\mathrm{ZnO}$ $\mathrm{NW}$ arrays, ZnO NT arrays, or $\mathrm{SiON} / \mathrm{ZnO} \mathrm{NT}$ arrays were synthesized on top of the $\mathrm{Si}_{3} \mathrm{~N}_{4}$ AR layer. To synthesize $\mathrm{ZnO}$ $\mathrm{NW}$ arrays on the surface of regular SCs, a $10 \mathrm{~nm}$ thick $\mathrm{ZnO}$ seed layer was sputter-deposited onto the $\mathrm{Si}_{3} \mathrm{~N}_{4}$ surface, and $\mathrm{ZnO} \mathrm{NW}$ arrays were synthesized on the surface of this via the hydrothermal growth (HTG) method [17, 18]. A mixed solution of $0.07 \mathrm{MZnO}\left(\mathrm{NO}_{3}\right)_{2} \cdot 6 \mathrm{H}_{2} \mathrm{O}$ and $0.07 \mathrm{M} \mathrm{C}_{6} \mathrm{H}_{12} \mathrm{~N}_{4}$ at $80^{\circ} \mathrm{C}$ was employed for $120 \mathrm{~min}$ in the HTG process. The typical diameters and lengths of the obtained $\mathrm{ZnO} \mathrm{NW}$ arrays were in the ranges of $100-200 \mathrm{~nm}$ and $400-500 \mathrm{~nm}$, respectively. These $\mathrm{ZnO}-\mathrm{NW}$-based devices are referred to as SC-C.

A two-step HTG method was used to synthesize $\mathrm{ZnO}$ NT arrays on the surface of regular SCs. To synthesize $\mathrm{ZnO}$ NT arrays with dimensions equal to those of the NW arrays, the HTG parameters mentioned above were used in the first HTG process. The second step was conducted at $80^{\circ} \mathrm{C}$ for $120 \mathrm{~min}$ and then at room temperature for $24 \mathrm{~h}$ for tube formation, which could be caused by the occurrence of a dissolving process at lower temperature $[19,20]$. In addition to increased surface roughness, the $\mathrm{ZnO}$ NT arrays are expected to alleviate the light absorption that occurs in conventional $\mathrm{ZnO}$ nanowires and overcome the issue of light reflection by offering a suitable effective refractive index. SCs based on ZnO NT arrays are referred to as SC-B.

Finally, a $150 \mathrm{~nm}$ thick $\mathrm{SiON}$ layer with a typical refractive index of 1.72 1.75 was coated onto the ZnO NT arrays using a plasma-enhanced chemical vapor deposition system. A mixed gas of $\mathrm{N}_{2} \mathrm{O}(350 \mathrm{sccm}), \mathrm{NH}_{3}(10 \mathrm{sccm}), 5 \% \mathrm{SiH}_{4}$ $(120 \mathrm{sccm})$, and $\mathrm{N}_{2}(400 \mathrm{sccm})$ was employed for the deposition process. The applied plasma power was $120 \mathrm{~W}$, the chamber pressure was 700 mTorr, and the substrate temperature was kept at $300^{\circ} \mathrm{C}$. These devices are referred to as SC-A. All four types of SC had a die size of $2.1 \mathrm{~cm} \times 3.4 \mathrm{~cm}$.

The light reflectance and refractive indexes of the prepared $\mathrm{SiON}$ films and $\mathrm{ZnO}$ nanostructures were characterized using a spectrophotometer and an ellipsometer, respectively. The current density-voltage $(J-V)$ and EQE characteristics of the prepared SCs were measured using a Science Tech $150 \mathrm{~W}$ under standard AM $1.5 \mathrm{G}$ test conditions $\left(100 \mathrm{~mW} / \mathrm{cm}^{2}\right.$ at $25^{\circ} \mathrm{C}$ ). 


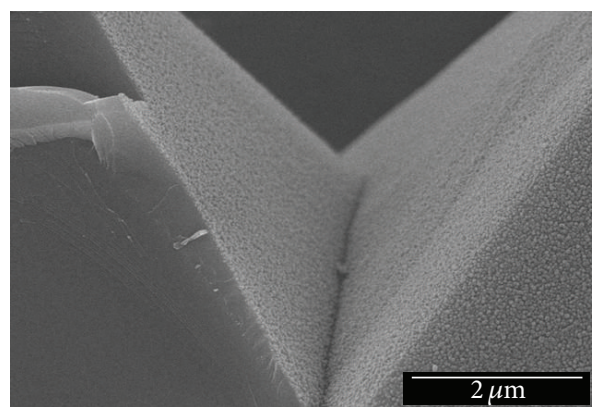

(a)

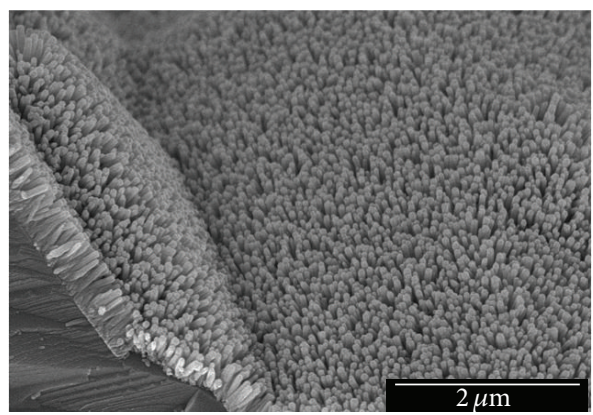

(c)

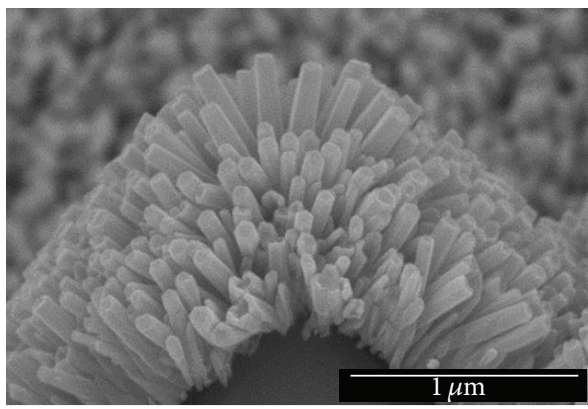

(e)

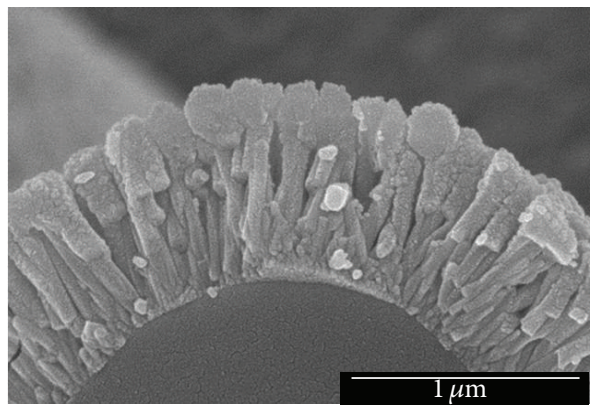

(g)

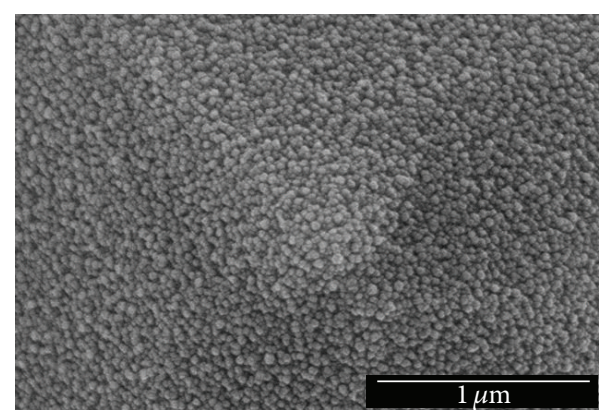

(b)

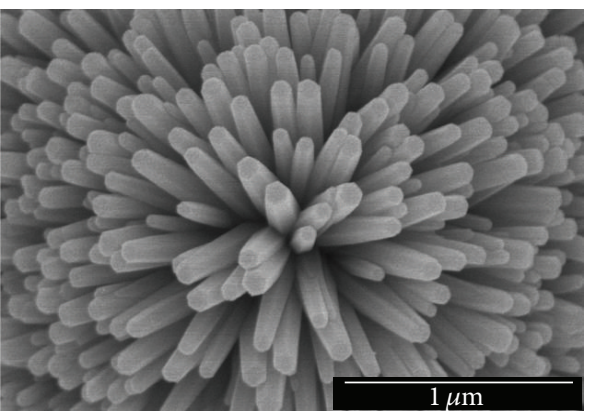

(d)

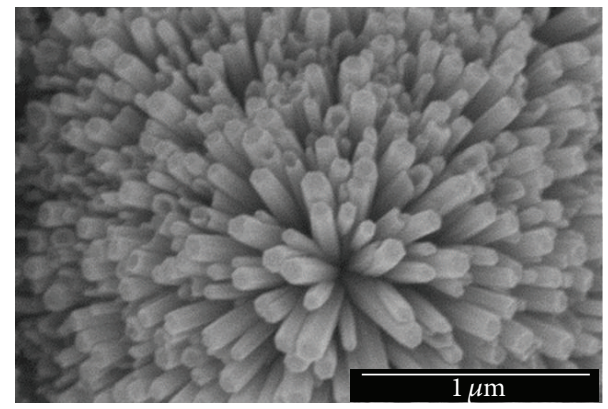

(f)

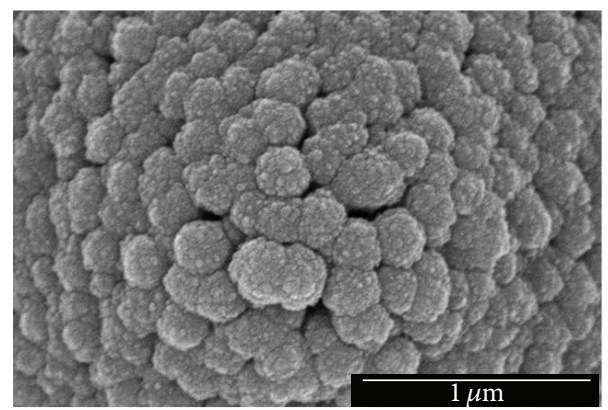

(h)

FIGURE 3: SEM images of surface morphology of prepared SCs. (a) Tilted- and (b) top-view images of regular SC, (c) tilted- and (d) top-view images of SC-C, (e) tilted- and (f) top-view images of SC-B, and (g) tilted- and (h) top-view images of SC-A.

\section{Results and Discussion}

The measured light transmittance and refractive index $(n)$ of the prepared $150 \mathrm{~nm}$ thick SiON film are shown in Figure 2. The film has a good transmittance of approximately $95 \%$ in the visible-light spectrum and a refractive index of 1.72-1.75.
The results reveal that a $150 \mathrm{~nm}$ thick $\mathrm{SiON}$ film deposited atop ZnO NT arrays does not significantly absorb sunlight. The film creates a graded-refractive-index scheme with the refractive index varying from $2.0 \sim 2.1\left(\mathrm{ZnO} / \mathrm{Si}_{3} \mathrm{~N}_{4}\right)$ [21] to $1.72 \sim 1.75$ ( $\mathrm{SiON}$ ) to 1 (air) for SC-A. Figure 3 shows top- and tilted-view scanning electron microscopy (SEM) images of 


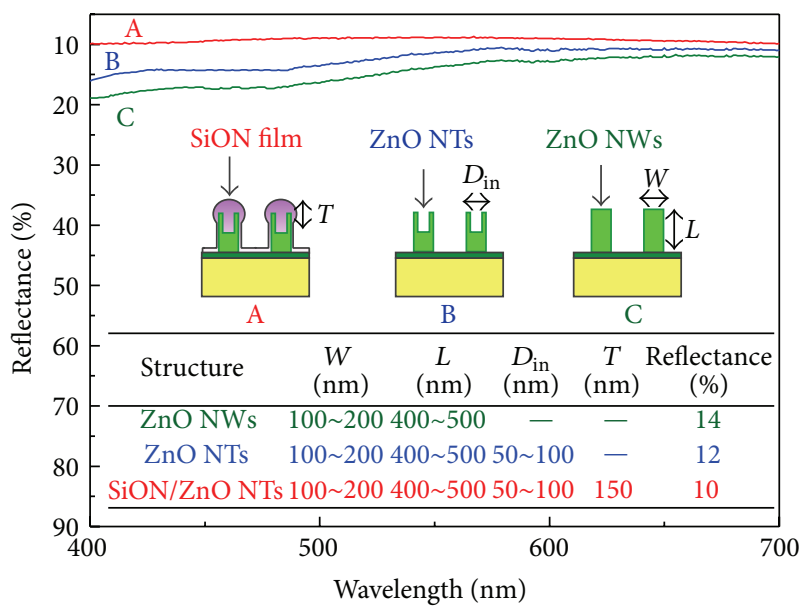

Figure 4: Measured reflectance of SiON/ZnO NT, ZnO NT, and $\mathrm{NW}$ arrays on $\mathrm{ZnO}$ (seed layer)/glass substrate. Thickness of $\mathrm{ZnO}$ seed layer is $10 \mathrm{~nm}$.

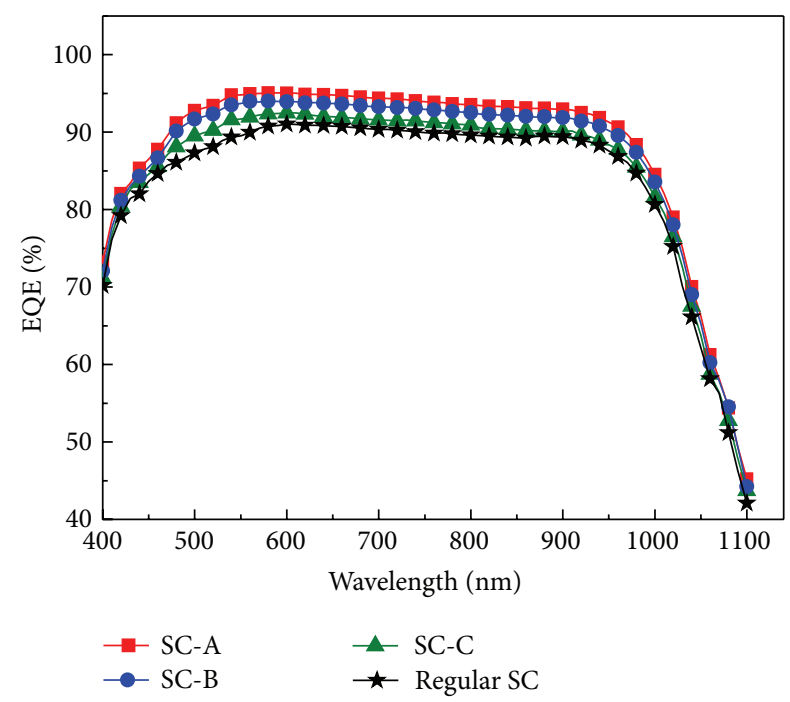

FIGURE 5: Measured EQE as a function of wavelength $\lambda$ for four types of SC with different surface roughness.

the surface morphology of the four types of SC. Distinctive nanostructures can be clearly observed on top of the $\mathrm{Si}_{3} \mathrm{~N}_{4} / \mathrm{n}$ $\mathrm{Si}$ surface. The micropyramid structures shown in Figures 3(a) and 3(b) were obtained via anisotropic etching of the $\mathrm{Si}$ surface using an alkaline solution. They have an average height and diameter of 3 and $5 \mu \mathrm{m}$, respectively. Figures 3(c) and 3(d) show the morphology of the HTG-prepared $\mathrm{ZnO}$ $\mathrm{NW}$ arrays atop the $\mathrm{Si}_{3} \mathrm{~N}_{4} / \mathrm{KOH}$-etched n-Si surface. Figures 3(e) and 3(f) show the ZnO NT arrays obtained from the second step of the HTG process. Figures $3(\mathrm{~g})$ and $3(\mathrm{~h})$ show $\mathrm{SiON} / \mathrm{ZnO}$ NT arrays with a sphere-like surface obtained via the deposition of SiON film onto the ZnO NT arrays.

The light reflectance of the $\mathrm{ZnO} \mathrm{NW}$ arrays, ZnO NT arrays, and SiON/ZnO NT arrays atop the $\mathrm{ZnO}$ seed layer $(10 \mathrm{~nm}) /$ glass substrate is shown in Figure 4 . It can be seen that the SiON/ZnO NT arrays have the best antireflective

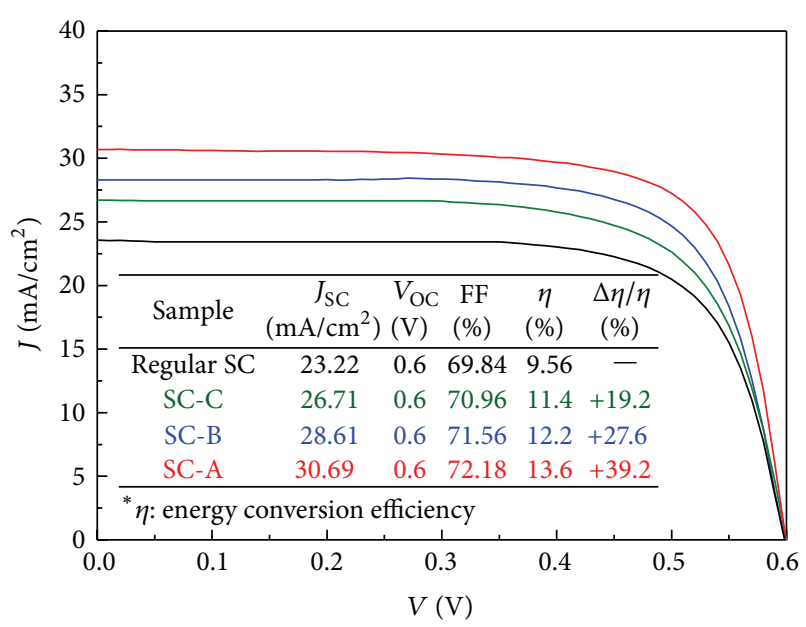

$$
\begin{aligned}
& \text { AM 1.5G area }=7.14 \mathrm{~cm}^{2} \\
& \text { Regular SC } \\
& \text { SC-C }
\end{aligned}
$$

Figure 6: Measured $J-V$ characteristics of regular SC, SC-C, SC-B, and SC-A. Inset shows measured cell parameters.

properties (around 10\%) in the visible-light spectrum, while the $\mathrm{ZnO}$ NWs arrays have reflectance of about $14 \%$. Figure 5 shows the measured external quantum efficiency (EQE) as a function of wavelength $\lambda$ for four types of SC with different surface roughness. It is found that the SC-A generally has the highest EQEs in the visible-light spectrum, and this is consistent with the reflectance data presented above. The high antireflection and EQE of the SiON/ZnO NT arrays can be attributed to the sphere-like morphology and the formation of a graded-refractive-index layer structure.

The $J-V$ characteristics of the fabricated SCs are shown in Figure 6 to examine the effectiveness of the SiON/ZnO NT arrays with regard to enhancing energy conversion efficiency. With the regular SC as a reference, details of the measured SC parameters, namely, short-circuit current density $\left(J_{\mathrm{SC}}\right)$, open-circuit voltage $\left(V_{\mathrm{OC}}\right)$, fill factor $(\mathrm{FF})$, energy conversion efficiency $(\eta)$, and enhanced energy conversion efficiency enhancement $(\Delta \eta / \eta)$ are listed in the inset. The surface roughening schemes provide different degrees of improvement in short-circuit current density and FF, which is attributed to a direct consequence of the broadband light trapping and the reduction in series resistance, as compared with that of the regular SCs. Note that the decreased series resistance is caused by the increase in electron and hole concentrations due to maximizing the light irradiation from air to the active region of cell. Similar experimental results with regard to improved FF have been reported for SCs with different surface structures [21-23]. In contrast, the opencircuit voltage shows no noticeable change, and this suggests that the parallel resistances of the three types of SC are not affected by surface roughening. As shown in Figure 6, SCA, SC-B, and SC-C show $\Delta \eta / \eta$ increases of $39.2 \%, 27.6 \%$, and $19.2 \%$, respectively, as compared to a regular SC under AM 1.5G $\left(100 \mathrm{~mW} / \mathrm{cm}^{2}\right)$ illumination. SC-A $(150 \mathrm{~nm}$ thick SiON film and $0.4 \mu \mathrm{m}$ long $\mathrm{ZnO} \mathrm{NT}$ arrays) shows the 


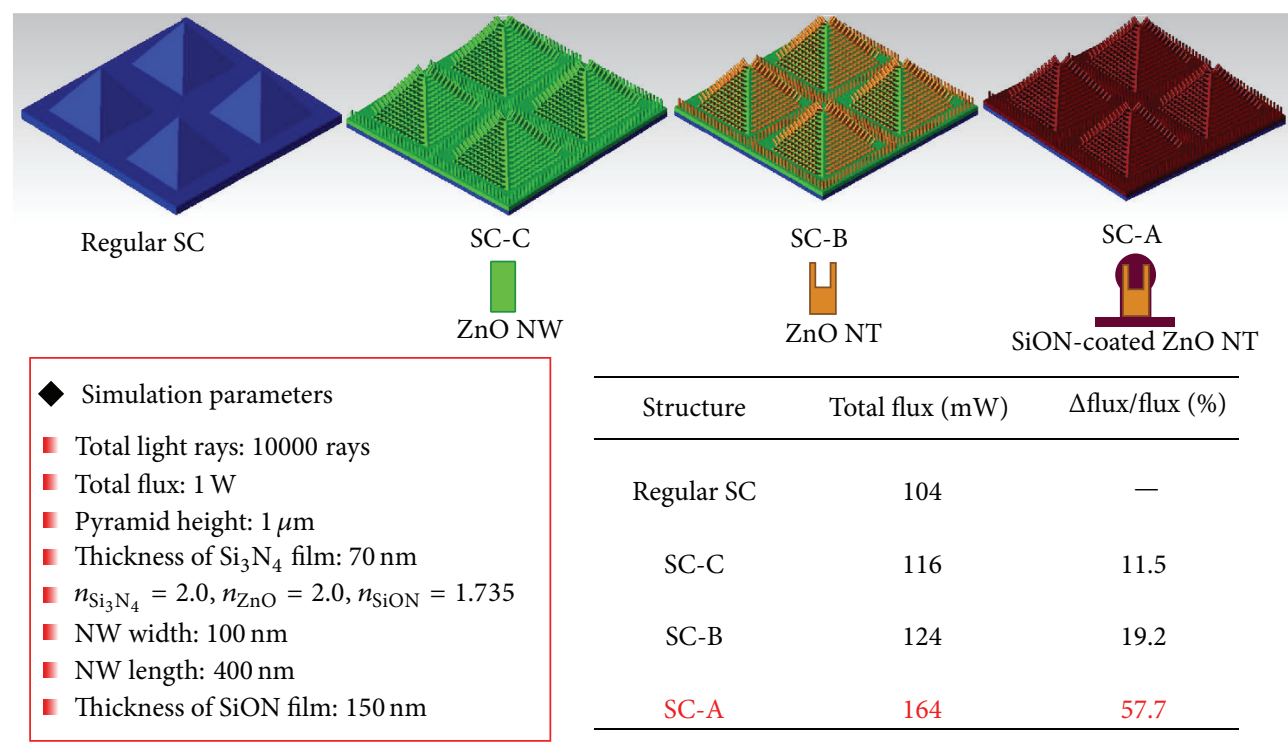

FIGURE 7: Simulation and calculation results of regular SC, SC-C, SC-B, and SC-A.

best improvement in cell performance. This is likely due to the effectiveness of this type of surface roughening, which promotes angular randomization of incident sunlight and enhances LTE. In addition, the $\mathrm{SiON} / \mathrm{ZnO} \mathrm{NT}$ arrays create a graded-refractive-index surface structure scheme, with the

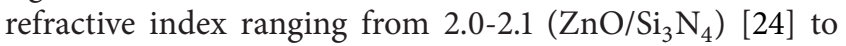
$1.72-1.75$ ( $\mathrm{SiON}$ ) to 1 (air). The use of $\mathrm{SiON}$ could maximize light irradiation from air to $\mathrm{Si}_{3} \mathrm{~N}_{4}$, and thus to the active region of the cell, without causing light reflection, because it offers a refractive index (1.72-1.75) that satisfies the optimized refractive index equation [25] $n_{\mathrm{opt}}=\sqrt{n_{1} \times n_{2}}$, where $n_{1}$ is the refractive index of $\mathrm{ZnO} / \mathrm{Si}_{3} \mathrm{~N}_{4}(n=2.0-2.1)$ [24] and $n_{2}$ is the refractive index of EVA $(n=1.51)$ [26].

The simulation results shown in Figure 7 demonstrate an LTE improvement trend that is similar to those obtained in the experimental findings. To further clarify the effectiveness of the surface roughening schemes, the light absorption efficiency of SCs with micropyramids, ZnO NW arrays atop the micropyramids, $\mathrm{ZnO} \mathrm{NT}$ arrays atop the micropyramids, and $\mathrm{SiON} / \mathrm{ZnO} \mathrm{NT}$ arrays atop the micropyramids was simulated using Tracepro [7]. The results are shown in Figure 7. The amount of total flux through the SCs with $\mathrm{SiON} / \mathrm{ZnO} \mathrm{NT}$ arrays atop the micropyramids is much larger than that of the SCs with micropyramids, which is in good agreement with the experimental findings. The Fresnel loss at the air $/ \mathrm{SiON} / \mathrm{ZnO} / \mathrm{Si}_{3} \mathrm{~N}_{4} / \mathrm{Si}$ surface is minimized through the combined effect of surface roughening and the refractiveindex-matched (RIM) scheme provided by the $\mathrm{SiON} / \mathrm{ZnO}$ NT arrays. The theoretical results agree well with the experimental ones. Although the structural parameters of the $\mathrm{SiON} / \mathrm{ZnO} \mathrm{NT}$ arrays need to be further optimized, the results provide a guideline for increasing the LTE of SCs.

\section{Conclusion}

The effectiveness of a surface roughening scheme was demonstrated with regard to improving the efficiency of
SCs with $\mathrm{SiON} / \mathrm{ZnO}$ NT arrays. The RIM SiON (150 nm in thickness)/ZnO NT (0.4 $\mu \mathrm{m}$ in length) structure significantly improved the efficiency of SC-A (by 39.2\%) under AM 1.5G $\left(100 \mathrm{~mW} / \mathrm{cm}^{2}\right)$ illumination compared with that of a regular SC. This enhancement can be attributed to the RIM SiON/ZnO NT array structure promoting the angular randomization of incident sunlight at the surface of the $\mathrm{Si}_{3} \mathrm{~N}_{4} / \mathrm{n}$-Si layer, effectively releasing surface reflection, and minimizing Fresnel loss. It is expected that the proposed RIM scheme with $\mathrm{SiON} / \mathrm{ZnO} \mathrm{NT}$ arrays can be applied to prepare high-energy-conversion-efficiency SCs.

\section{Conflict of Interests}

The authors declare that there is no conflict of interests regarding the publication of this paper.

\section{Acknowledgments}

This work was supported by the Ministry of Science and Technology (MOST) of Taiwan, under Grant MOST 1032221-E-006-132 and the National Science Council (NSC) of Taiwan, under Grant NSC 102-2221-E-006-217-MY2. The authors would like to thank the National Nano Device Laboratories and the Center for Micro/Nano Science and Technology, National Cheng Kung University, Taiwan, for equipment access and financial and technical support.

\section{References}

[1] C.-E. Lee, Y.-C. Lee, H.-C. Kuo, T.-C. Lu, and S.-C. Wang, "Further enhancement of nitride-based near-ultraviolet verticalinjection light-emitting diodes by adopting a roughened meshsurface," IEEE Photonics Technology Letters, vol. 20, no. 10, pp. 803-805, 2008. 
[2] M. Berginski, J. Hüpkes, M. Schulte et al., "The effect of front $\mathrm{ZnO}: \mathrm{Al}$ surface texture and optical transparency on efficient light trapping in silicon thin-film solar cells," Journal of Applied Physics, vol. 101, no. 7, Article ID 074903, 2007.

[3] H. W. Huang, C. H. Lin, K. Y. Lee et al., "Enhanced light output power of GaN-based vertical-injection light-emitting diodes with a 12 -fold photonic quasi-crystal by nano-imprint lithography," Semiconductor Science and Technology, vol. 24, no. 8, Article ID 085008, 2009.

[4] R. Sivakumar, K. Punitha, C. Sanjeeviraja, and R. Gopalakrishnan, "Morphology control of $\mathrm{ZnO}$ nanostructures by catalystfree and seed-mediated simple aqueous solution growth method," Materials Letters, vol. 121, pp. 141-144, 2014.

[5] K. V. Gurav, M. G. Gang, S. W. Shin et al., "Gas sensing properties of hydrothermally grown $\mathrm{ZnO}$ nanorods with different aspect ratios," Sensors and Actuators B: Chemical, vol. 190, pp. 439-445, 2014.

[6] L.-K. Yeh, K.-Y. Lai, G.-J. Lin et al., "Giant efficiency enhancement of GaAs solar cells with graded antireflection layers based on syringelike $\mathrm{ZnO}$ nanorod arrays," Advanced Energy Materials, vol. 1, no. 4, pp. 506-510, 2011.

[7] Y. C. Tu, S. J. Wang, G. Y. Lin et al., "Enhanced light output of vertical GaN-based LEDs with surface roughened by refractiveindex-matched $\mathrm{Si}_{3} \mathrm{~N}_{4} / \mathrm{GaN}$ nanowire arrays," Applied Physics Express, vol. 7, no. 4, Article ID 042101, 2014.

[8] K. J. Chen, F. Y. Hung, S. J. Chang, and S. J. Young, "Optoelectronic characteristics of UV photodetector based on $\mathrm{ZnO}$ nanowire thin films," Journal of Alloys and Compounds, vol. 479, no. 1-2, pp. 674-677, 2009.

[9] T.-Y. Chen, H.-I. Chen, C.-S. Hsu et al., "ZnO-nanorod-based ammonia gas sensors with underlying $\mathrm{Pt} / \mathrm{Cr}$ interdigitated electrodes," IEEE Electron Device Letters, vol. 33, no. 10, pp. 1486-1488, 2012.

[10] Y.-C. Tu, S.-J. Wang, J.-C. Lin et al., "Light output improvement of GaN-based light-emitting diodes using hydrothermally grown ZnO nanotapers," Japanese Journal of Applied Physics, vol. 52, no. 6, supplement, Article ID 06GG13, 2013.

[11] F.-S. Tsai, S.-J. Wang, Y.-C. Tu et al., "Preparation of p-SnO/n$\mathrm{ZnO}$ heterojunction nanowire arrays and their optoelectronic characteristics under UV illumination," Applied Physics Express, vol. 4, no. 2, Article ID 25002, 2011.

[12] J. L. Zhao, X. M. Li, J. M. Bian, W. D. Yu, and X. D. Gao, "Structural, optical and electrical properties of $\mathrm{ZnO}$ films grown by pulsed laser deposition (PLD)," Journal of Crystal Growth, vol. 276, no. 3-4, pp. 507-512, 2005.

[13] J. Yi, J. M. Lee, and W. I. Park, "Vertically aligned ZnO nanorods and graphene hybrid architectures for high-sensitive flexible gas sensors," Sensors and Actuators B: Chemical, vol. 155, no. 1, pp. 264-269, 2011.

[14] Y. Li, F. D. Valle, M. Simonnet, I. Yamada, and J.-J. Delaunay, "High-performance UV detector made of ultra-long $\mathrm{ZnO}$ bridging nanowires," Nanotechnology, vol. 20, no. 4, Article ID 045501, 2009.

[15] Y. Liu, Z. Lin, K. S. Moon, and C. P. Wong, "Novel ZnO nanowires/silicon hierarchical structures for superhydrophobic, low reflection, and high efficiency solar cells," in Proceedings of the IEEE 61st Electronic Components and Technology Conference (ECTC '11), pp. 2114-2118, Lake Buena Vista, Fla, USA, May-June 2011.

[16] X. Yu, D. Wang, D. Lei, G. Li, and D. Yan, "Efficiency improvement of silicon solar cells enabled by $\mathrm{ZnO}$ nanowhisker array coating," Nanoscale Research Letters, vol. 7, article 306, 2012.
[17] P.-Y. Yang, J.-L. Wang, P.-C. Chiu et al., " $\mathrm{pH}$ sensing characteristics of extended-gate field-effect transistor based on aldoped $\mathrm{ZnO}$ nanostructures hydrothermally synthesized at low temperatures," IEEE Electron Device Letters, vol. 32, no. 11, pp. 1603-1605, 2011.

[18] K. H. Baik, H. Kim, J. Kim, S. Jung, and S. Jang, "Nonpolar light emitting diode with sharp near-ultraviolet emissions using hydrothermally grown $\mathrm{ZnO}$ on p-GaN," Applied Physics Letters, vol. 103, no. 9, Article ID 091107, 2013.

[19] A. Wei, X. W. Sun, C. X. Xu et al., "Growth mechanism of tubular $\mathrm{ZnO}$ formed in aqueous solution," Nanotechnology, vol. 17, no. 6, pp. 1740-1744, 2006.

[20] A. Wei, X. W. Sun, C. X. Xu, Z. L. Dong, M. B. Yu, and W. Huang, "Stable field emission from hydrothermally grown $\mathrm{ZnO}$ nanotubes," Applied Physics Letters, vol. 88, no. 21, Article ID 213102, 2006.

[21] H. C. Chen, C. C. Lin, H. W. Han et al., "Enhanced efficiency for c-Si solar cell with nanopillar array via quantum dots layers," Optics Express, vol. 19, no. 19, pp. A1141-A1147, 2011.

[22] I. Lee, D. G. Lim, S. H. Lee, and J. Yi, “The effects of a double layer anti-reflection coating for a buried contact solar cell application," Surface and Coatings Technology, vol. 137, no. 1, pp. 86-91, 2001.

[23] S. K. Sardana, V. S. N. Chava, E. Thouti et al., "Influence of surface plasmon resonances of silver nanoparticles on optical and electrical properties of textured silicon solar cell," Applied Physics Letters, vol. 104, no. 7, Article ID 073903, 2014.

[24] F. K. Shan and Y. S. Yu, "Band gap energy of pure and Al-doped $\mathrm{ZnO}$ thin films," Journal of the European Ceramic Society, vol. 24, no. 6, pp. 1869-1872, 2004.

[25] X. Da, X. Guo, L. Dong, Y. Song, W. Ai, and G. Shen, "The silicon oxynitride layer deposited at low temperature for high-brightness GaN-based light-emitting diodes," Solid-State Electronics, vol. 50, no. 3, pp. 508-510, 2006.

[26] E. Klampaftis and B. S. Richards, "Improvement in multicrystalline silicon solar cell efficiency via addition of luminescent material to EVA encapsulation layer," Progress in Photovoltaics: Research and Applications, vol. 19, no. 3, pp. 345-351, 2011. 

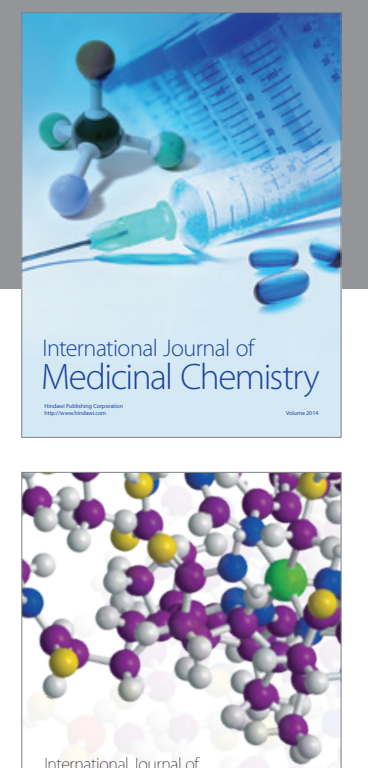

\section{Carbohydrate} Chemistry

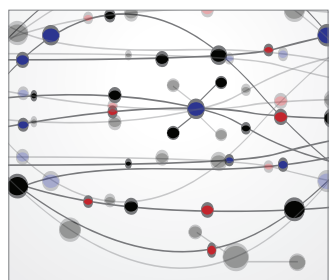

The Scientific World Journal
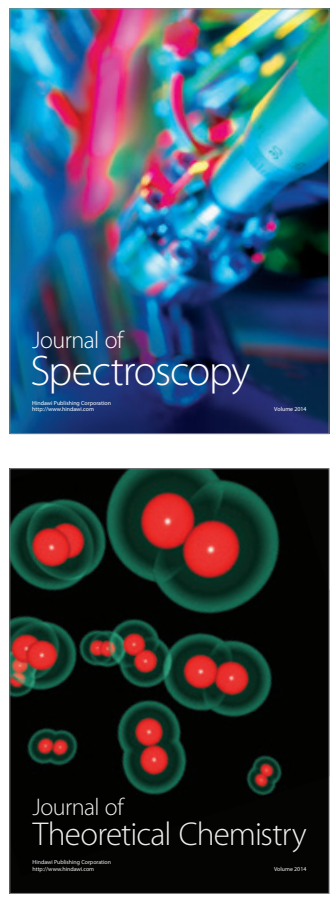
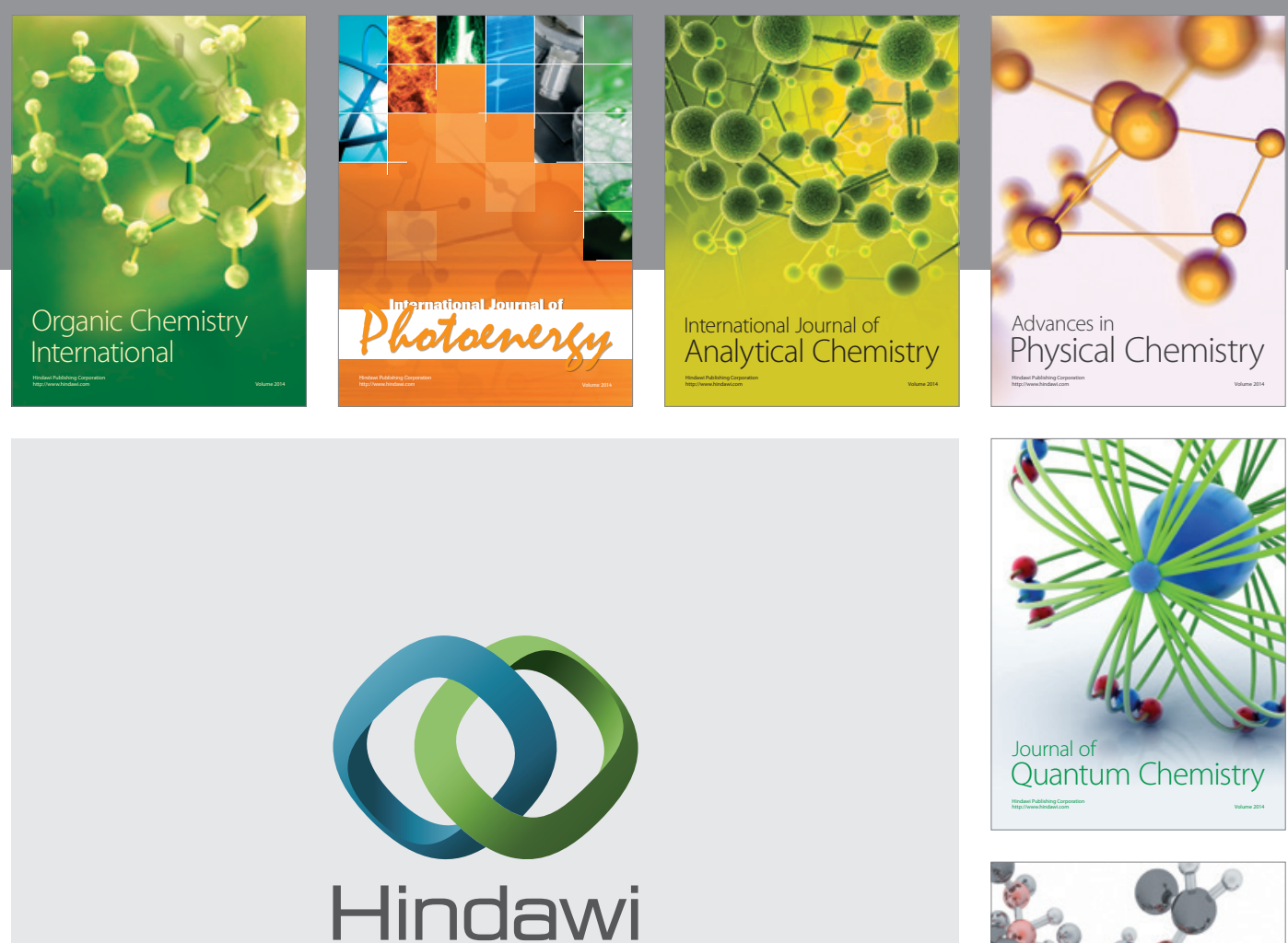

Submit your manuscripts at

http://www.hindawi.com

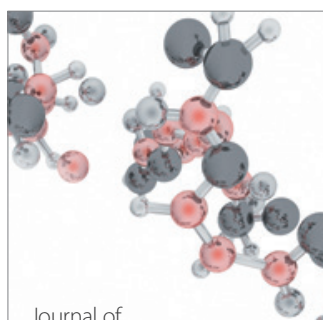

Analytical Methods

in Chemistry

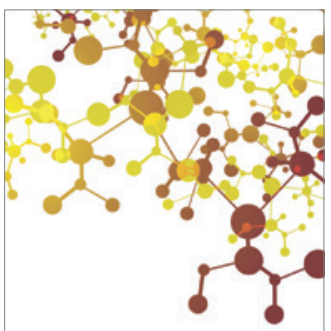

Journal of

Applied Chemistry

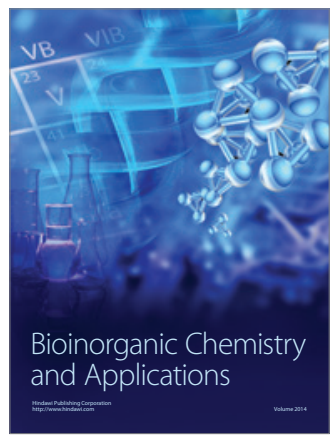

Inorganic Chemistry
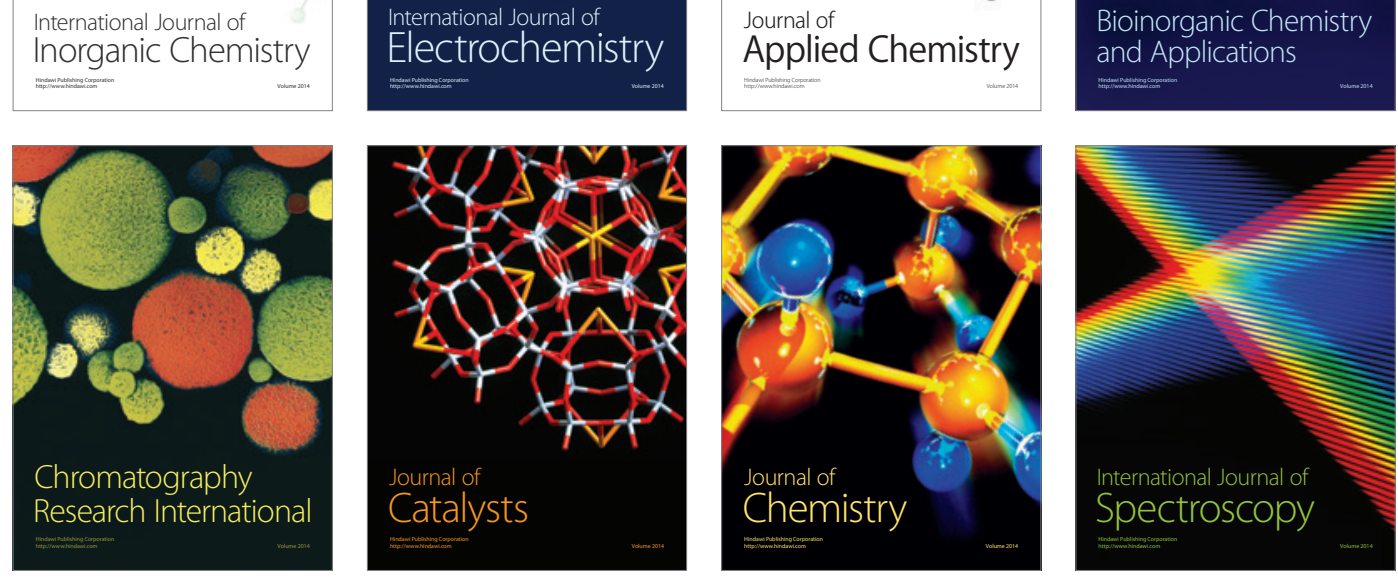